\title{
Muerte perinatal por listeriosis
}

\author{
Perinatal death from listeriosis
}

\author{
Mariajosé Galup-Leyva', Alessandra Maggi- \\ Panato', Juliet Suárez-Caro', Pamela Carpio- \\ Vargas', Melanie Matzunaga-Angeludis', \\ Jimena García-Baldeón', Inés Adriana Vilca \\ Luna', Giovanna Hernández-Guzmán', \\ Robert Cumpa-Quiroz ${ }^{2}$
}

Galup-Leyva M, Maggi-Panato A, Suárez-Caro J, Carpio-Vargas P, Matzunaga-Angeludis M, García-Baldeón J,Vilca Luna IA, Hernández-Guzmán G, Cumpa-Quiroz R2. Muerte perinatal por listeriosis. Rev Soc Peru Med Interna. 2021;34(3): I I9-1 22. https://doi.org/10.36393/spmi.v34i3.613

\section{RESUMEN}

Mujer de 35 años, con 22 semanas de gestación, presentó fiebre sin origen determinado y disminución de los movimientos fetales, evolucionando con muerte fetal por infección por Listeria monocytogenes, evidenciada por hemocultivos y el estudio anatomo- patológico del feto y la placenta.

Palabras clave: Listeria monocytogenes, listeriosis, fiebre, óbito fetal, embarazo.

\section{ABSTRACT}

A 35-year-old woman, with 22 weeks of gestation, presented fever without a determined origin and decreased fetal movements, evolving with fetal death due to Listeria monocytogenes infection, evidenced by blood cultures and the pathological study of the fetus and placenta.

Keywords: Listeria monocytogenes, listeriosis, fever, fetal death, pregnancy.

\section{INTRODUCCIÓN}

La listeriosis es una enfermedad producida por la bacteria gram positiva móvil, Listeria monocytogenes, la cual se adquiere al consumir alimentos contaminados tales como lácteos no pasteurizados o vegetales crudos. ${ }^{1}$

La infección es asintomática en individuos sanos, mientras que en inmunosuprimidos la clínica puede presentarse

I Interna de la Escuela de Medicina. Facultad de Ciencias de la Salud. Universidad Peruana de Ciencias Aplicadas. Clínica Padre Luis Tezza, Lima, Perú.

2 Médico internista. Clínica Padre Luis Tezza, Lima, Perú. desde un cuadro pseudogripal con fiebre, artralgias y cefalea o con un cuadro grave como endocarditis o bacteriemia. Asimismo, dentro de este grupo, el número de casos es predominante y clínicamente relevante en las gestantes por el gran riesgo de mortalidad materno-fetal que ocasiona. ${ }^{2}$ La listeriosis al localizarse en la placenta infecta al feto, produciendo durante el primer trimestre abortos septicos y muerte fetal; mientras que durante el tercer trimestre se asocia a coriamnionitis, parto prematuro, deterioro del crecimiento y muerte perinatal. ${ }^{3-4}$ Según la OMS, la listeriosis se presenta en las gestantes en el $43 \%$ del total de casos y $14 \%$ ocurren durante el embarazo tardío. ${ }^{5}$ Considerando la afección grave que conlleva, cuando una gestante presenta fiebre inexplicable, se debe considerar la listeriosis, ya que de esta forma un diagnóstico y manejo oportuno mejora el pronóstico de los recién nacidos. ${ }^{6}$

\section{PRESENTACIÓN DEL CASO}

Mujer de 35 años, gestante de 22 semanas, fue hospitalizada con un tiempo de enfermedad de cuatro días, caracterizado por la aparición de fiebre acompañado de dolor vulvar, dolor abdominal, malestar general y disminución de la frecuencia de los movimientos fetales. Había sido previamente evaluada por el consultorio de ginecología y emergencia en el segundo y tercer día de enfermedad sin diagnóstico preciso y tratada solo con sintomáticos. Ante la persistencia 
de fiebre y la sensación de disminución de los movimientos fetales acudió al servicio de emergencia y fue hospitalizada para determinar el diagnóstico y ante el riesgo de viabilidad de gestación. Funciones biológicas conservadas.

El examen físico mostró una orofaringe congestiva; cuello y pulmones normales; ruidos cardiacos normales, un soplo sistólico multifocal; abdomen grávido con altura uterina de $20 \mathrm{~cm}$, movimientos fetales presentes, latidos fetales 148/ min; neurológico sin alteraciones.

Los exámenes auxiliares revelaron anemia ( $\mathrm{Hb} 9,2 \mathrm{~g} / \mathrm{dl}$ ) con hierro sérico disminuido (24 ug/dl), PCR en 16,47 mg/ dl, ferritina sérica en $213,5 \mathrm{ng} / \mathrm{ml}$, y enzimas hepáticas elevadas (TGO 129 U/L, TGP $121 \mathrm{U} / \mathrm{L}$, FA $190 \mathrm{U} / \mathrm{L}$ ). Examen de orina: hematuria (25-30 hematíes x campo).

Radiografía de tórax, ecografía abdominal y transvaginal sin hallazgos relevantes. Urocultivo negativo y se tomó muestras para hemocultivos.

Al segundo día de hospitalización, la paciente refirió aumento de la intensidad del dolor abdominal y sangrado

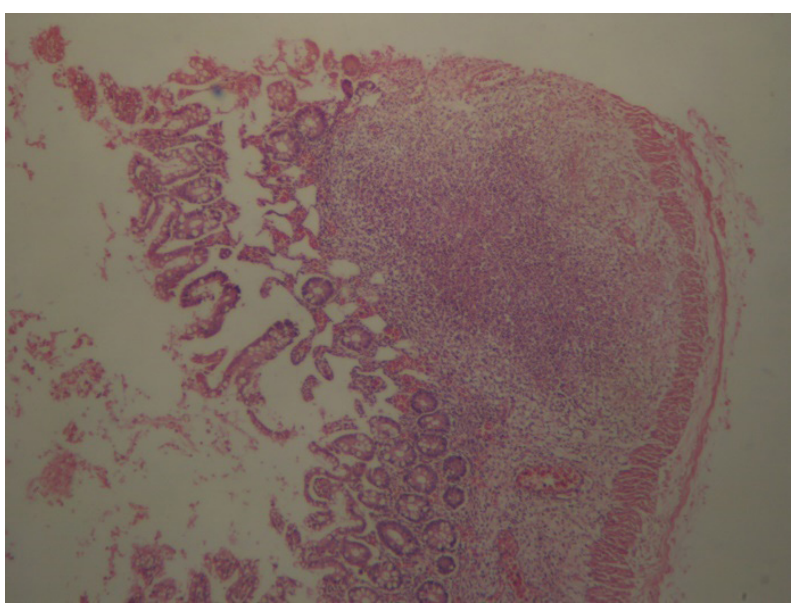

Figura I. Mucosa colónica con cambios isquémicos tempranos, congestión vascular y denso infiltrado inflamatorio en la lámina propia que, a mayor aumento, demostró estar constituido principalmente por neutrófilos y linfocitos.

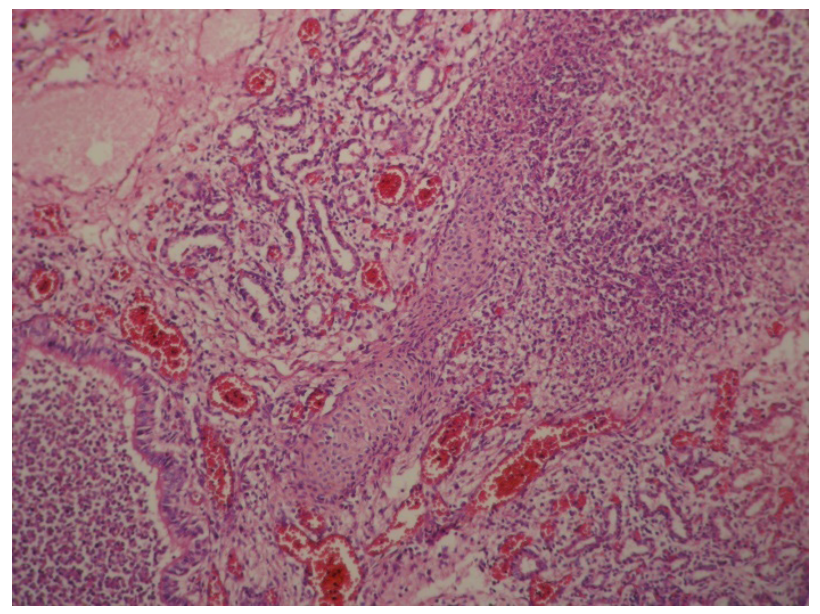

Figura2. Tejido pulmonar con congestión vascular e infiltrado inflamatorio neutrófilo a nivel de las vías aéreas (ángulo inferior izquierdo). rojo vivo escaso. Con fiebre persistente $\left(\mathrm{T}^{\mathbf{0}} 39.2^{\circ} \mathrm{C}\right)$ por lo que se administró un antipirético. En el tacto vaginal se evidenció dilatación 0 ; altura de presentación -3; cuello uterino blando, centralizado y sangrado vaginal rutilante y activo. Dolor intermitente cada 3 minutos, no se evidenciaron contracciones uterinas. Se administró tocolíticos. La paciente persistió con fiebre $\left(38^{\circ} \mathrm{C}\right)$, se evidenció taquicardia fetal (177-189/min). En el tacto vaginal se halló dilatación de $3 \mathrm{~cm}$, altura de presentación -2 , por lo que se sospechó de amenaza de parto prematuro y sufrimiento fetal agudo. Ocurrido el parto prematuro, se halló un óbito fetal y líquido amniótico amarillo, y se realizó un legrado uterino.

A las horas del legrado, la fiebre cedió y los exámenes de laboratorio se normalizaron. La paciente se estabilizó y fue dada de alta dos días después del ingreso con tratamiento antibiótico para corioamnionitis.

A los dos días del alta, un hemocultivo dio positivo para Listeria monocytogenes, sensible a ampicilina y gentamicina. A los 10 días del alta, la paciente fue evaluada en la consulta externa, encontrándosele en buenas condiciones generales y biometría hemática normal.

En la necropsia fetal se halló un feto de 22 semanas de gestación, de sexo masculino, sin malformaciones congénitas, con órganos y sistemas inmaduros en relación con la edad gestacional, llamando la atención algunos focos de infiltrado inflamatorio agudo en el parénquima pulmonar y colon. Pulmones: parénquima inmaduro y con microabscesos. Colon: foco de microabsceso en la submucosa. La biopsia de placenta mostró una placenta de segundo trimestre con hialinosis septal e intervellosa $\mathrm{y}$ focos de inflamación aguda. Onfalitis y corioamnionitis aguda.

En el estudio anatomopatológico del óbito fetal se evidenciaron microabscesos en colon (Figura 1) y pulmones (Figura 2). Además, tras la biopsia de la placenta, se encontraron signos de corioamnionitis y características inflamatorias agudas como onfalitis, hialinosis septal e intervellosa y focos de inflamación aguda lo cual es sugestivo de un proceso infeccioso subyacente.

\section{DISCUSIÓN}

La listeriosis es una enfermedad transmitida por alimentos (ETA) poco común en la población general $(0,29$ casos por 100000 personas); sin embargo, la incidencia aumenta en pacientes inmunocomprometidos como embarazadas, fetos, neonatos y adultos mayores. ${ }^{7,8}$ Se menciona que la incidencia en mujeres embarazadas aumenta a 3,0 casos por 100000 y esta es mayor cuando se trata de gestantes hispanas $(7,0$ casos por 100000$) .{ }^{8}$ Cabe resaltar que, a comparación de otras ETAs, esta puede presentar una elevada mortalidad de hasta $30 \% .{ }^{9}$ Un estudio peruano del 2008 reportó que de 117 gestantes estudiadas, 2\% presentó listeriosis. ${ }^{10}$ Por otro lado, se han reportado ciertos datos sobre la presencia de esta bacteria en canales porcinos $(13,9$ $\pm 6.1 \%)$ y en queso fresco de vaca $(20.7 \%){ }^{11,12}$ Asimismo, en el 2015, un estudio en un hospital peruano reportó que 
la $L$. monocytogenes fue la primera causa de meningitis neonatal. ${ }^{13}$

La listeriosis produce un cuadro clínico muy variable, desde una presentación asintomática o manifestaciones leves como fiebre, malestar general, diarrea, mialgias, hasta complicaciones severas como parto prematuro, corioamnionitis y óbito fetal. ${ }^{3}$ En este caso, la paciente presentó como síntoma principal fiebre continua asociada a dolor abdominal, dolor de garganta, tos seca, disminución de movimientos fetales y taquicardia fetal. Lo mencionado coincide con lo reportado que la fiebre es el síntoma más frecuente de listeriosis en las gestantes. ${ }^{5}$ De igual manera, en el 2017, se reportaron cuatro casos de listeriosis en el embarazo, en un hospital nacional, donde el síntoma en común fue fiebre. ${ }^{15}$ También, se ha descrito, en las gestantes con listeriosis, disminución de los movimientos fetales, taquicardia fetal, dolor abdominal, contracciones, sangrado vaginal y ruptura prematura de membranas. ${ }^{3}$ Además, se ha descrito que dicha enfermedad puede presentarse con síntomas respiratorios pseudogripales, como los que fueron referidos por la paciente inicialmente. ${ }^{14}$

El aislamiento de L. monocytogenes suele realizarse mediante hemocultivo (materna o neonatal), líquido cefalorraquídeo (LCR) neonatal, líquido amniótico, la cavidad uterina o la placenta (16). El cultivo de la placenta es el método más sensible, se recomienda realizarlo junto con el hemocultivo, ya que las tasas de positividad de las dos pruebas son de $80 \%$ y $50 \%$, respectivamente. ${ }^{5}$ En nuestro caso, el primer examen que relacionó el cuadro clínico de la paciente con listeriosis fue el hemocultivo, y se obtuvieron dos hemocultivos positivos a L. monocytogenes. Actualmente no se recomienda realizar coprocultivo por la baja sensibilidad. ${ }^{5}$

En el estudio anatomopatológico del óbito fetal se evidenciaron microabcesos en colon y pulmones. Esta presentación es típica de la granulomatosis infantiséptica, la cual es una complicación severa de dicha enfermedad y cuya mortalidad oscila entre $30-50 \%$. Esta se presenta luego de la aspiración de líquido amniótico infectado y se caracteriza por fiebre materna, corioamnionitis y parto prematuro, lo cual fue presentado por nuestra paciente. ${ }^{3}$

El tratamiento de elección para la listeriosis es ampicilina o penicilina a altas dosis por 14 días. ${ }^{17}$ En nuestro caso, la paciente recibió ceftriaxona y clindamicina con el objetivo de cubrir bacterias gram positivas y anaerobios. Por ello, se evidenció la mejoría clínica de la paciente a pesar de no recibir el tratamiento de elección antes mencionado.

En conclusión, a pesar que la listeriosis es una infección poco frecuente, dada su alto impacto durante el embarazo y en neonatos, ante la sospecha de bacteriemia en una gestante, a partir de la semana 20, es recomendable solicitar hemocultivos, sobre todo ante la presencia de corioamnionitis. ${ }^{2}$ De igual manera, consideramos que se debe hacer énfasis en las medidas de prevención durante los controles prenatales; por ejemplo, aconsejar la adecuada selección e higiene de la preparación de alimentos, en especial los de origen animal, ya que en nuestro país hay evidencia del aislamiento de la bacteria en canales porcinos, así como en productos lácteos, entre otros.

\section{REFERENCIAS BIBLIOGRÁFICAS}

I. Abarca V K. Infecciones en la mujer embarazada transmisibles al feto. Rev Chil infectología. 2003;20:4l-6. URL disponible en: http:// www.scielo.cl/scielo.php?script=sci_arttext\&pid=S07 I 610182003020100007\&lng=es\&nrm=iso\&tlng=es

2. Gotuzzo E. Listeriosis en embarazo. Rev Medica Hered. 20 I 7;28(I):34.URL disponible en:http://www.scielo.org.pe/scielo.php?script=sci_ arttext\&pid=S $10|8-| 30 \times 20|7000| 0000 \mid \& \operatorname{lng}=e s \& n r m=i s o \& t \operatorname{lng}=$ es

3. Cisternas A V, Lagos NN, Galstuch JL, González CR, García CC, Díaz JT. Infeccion por Listeria monocytogenes y embarazo con buen resultado perinatal. Rev Chil Obs Ginecol. 2002;67(3):237-4I.

4. Egloff C, Sibiude J, Couffignal C, Mandelbrot L, Picone O. Causes and consequences of fever during pregnancy: $A$ retrospective study in a gynaecological emergency department. J Gynecol Obstet Hum Reprod. 2020 Nov;49(9):I01899. doi: 10.1016/j.jogoh.2020.101899. Epub 2020 Aug 24. PMID: 32853830; PMCID: PMC7444605.

5. Wang Z, Tao X, Liu S, Zhao Y, Yang X. An update review on Listeria infection in pregnancy. Infect Drug Resist. 202। May 26; | 4:1967-1978. doi: I0.2 I47/IDR.S3 I3675. PMID: 34079306; PMCID: PMC8I65209.

6. Macías, J. F., Cano, S., Sabay, H., Garzón Avila, H., Herdoíza Arroyo, L., \& Torres, G. (20I8). Corioamnionitis por Listeria monocytogenes: reporte de caso clínico. Metro Ciencia, 26(2), 72-75. Recuperado a partir de https://revistametrociencia.com.ec/index.php/revista/ article/view/47

7. Pérez Díaz L, de Sotomayor Merino JÁ, Guichot Muñoz M, Chacón Aguilar C, Rodríguez Luque JL, Avilés Mejías S, et al. Muerte fetal intraútero secundaria a corioamnionitis aguda por Listeria monocytogenes. Progresos Obstet y Ginecol. 2008;5 I(3): I7880. URL disponible en: https://www.elsevier.es/es-revistaprogresos-obstetricia-ginecologia- I 5 I-articulo-muerte-fetalintrautero-secundaria-corioamnionitis-S030450I 3087 I 0732

8. Vital signs: Listeria illnesses, deaths, and outbreaks - United States, 2009-20I I references. Ann Emerg Med. 20 I3;62(5):536-7.

9. Rodríguez-Auad JP, Rodríguez-Auad JP. Panorama de la infección por Listeria monocytogenes. Rev Chil infectología. 2018;35(6):64957. URL disponible en: http://www.scielo.cl/scielo.php?script=sci_ arttext\&pid=S07 | 6- 10182018000600649 \&lng=es\&nrm=iso\&tlng=e

10. Baca-Neglia H, Piña-Baca F, Lam-Gonzales J, Gomez-Aguilar D. Listeriosis en gestantes. Lima, Perú. Rev Peru Obstet y Enfermería. 2008;4(I):2-6. URL disponible en: https://www.aulavirtualusmp.pe/ ojs/index.php/rpoe/article/view/558

II. Barrientos H Edy Waldo, Lucas L Juan Raúl, Ramos D Daphne, Rebatta T Mónica, Arbaiza F Teresa. Presencia de Listeria monocytogenes en canales porcinas en Lima, Perú. Rev. investig. vet.Perú.20 I5;26(I):I35-I39.Disponible en:http://www.scielo.org.pe/ scielo.php?script $=$ sci_arttext\&pid=SI609-9II 7201500 01000 I6\&lng=es. http://dx.doi.org/I0.1538I/rivep.v26il.10907.

12. Espinoza MAna, De La Torre B Magali, Salinas F Marianella, Sánchez P Víctor. Determinación de Listeria monocytogenes en quesos frescos de producción artesanal que se expenden en los mercados del distrito de Ica, enero - marzo 2003. Rev. perú. med. exp. salud publica. 2004; 2I(2):7I-75. URL disponible en: http:// www.scielo.org.pe/scielo.php?script=sci_arttext\&pid=SI 72646342004000200003\&lng=es.

13. Lewis G, Schweig M, Guillén-Pinto D, Rospigliosi ML. Meningitis neonatal en un hospital general de Lima, Perú, 2008 al 2015. Rev Peru Med Exp Salud Publica. 2017;34(2):233-8. URL disponible en: http://www.scielo.org.pe/scielo.php?script=sci_arttext\&pid=SI 726463420 I 70002000 I 0\&Ing=es\&nrm=iso\&tlng=es

14. Mylonakis E, Paliou M, Hohmann EL, Calderwood SB, Wing EJ. Listeriosis during pregnancy: a case series and review of 222 cases. Medicine (Baltimore). 2002 Jul;8I (4):260-9. doi: I0. I097/00005792200207000-00002. PMID: I2 I6988I.

I5. Diaz-Herrera J, Salvador-Pichilingue J, Maguiña-Vargas C, CokGarcia J. Listeriosis in pregnancy. Rev Medica Hered. 20I7;28(I):29- 
32. URL disponible en: http://www.scielo.org.pe/scielo. php?script=sci_arttext\&pid=SI0 | $8-|30 X 20| 7000|00005 \&| n g=e s \&$ nrm=iso\&tlng=es

16. Lamont RF, Sobel J, Mazaki-Tovi S, Kusanovic JP,Vaisbuch E, Kim SK, Uldbjerg N, Romero R. Listeriosis in human pregnancy: a systematic review. J Perinat Med. 20II May;39(3):227-36. doi: 10.15I5/ jpm.20II.035. Epub 20II Apr 25. PMID: 2I5I7700; PMCID: PMC3593057.

17. Committee Opinion No. 614: Management of pregnant women with presumptive exposure to Listeria monocytogenes. Obstet Gynecol. 2014 Dec;124(6):I24I-I244. doi: 10.1097/0I. AOG.000045750I.73326.6c. PMID: 254II 758 .

\section{CORRESPONDENCIA:}

Jimena García-Baldeón,

jimena9727@gmail.com

AGRADECIMIENTOS: Al Dr. Pedro Brasini Chacón Yupanqui, médico patólogo de la Clínica Padre Luis Tezza.

Fecha de recepción: 20-08-2021.

Fecha de aceptación: 06-09-202I.

Conflicto de interés: ninguno, según los autores.

Financiamiento: por los autores. 